\title{
Status of the left ventricle after arterial switch operation for transposition of the great arteries
}

\author{
Hemodynamic and echocardiographic evaluation
}

Background: The potential for improved preservation of systemic ventricular function represents an important reason for the increasing popularity of the arterial switch operation. In support of this expectation, prior studies in patients early after arterial switch operation have found normal ventricular contractility and function. This study was conducted to extend those observations to up to 10 years of follow-up and to directly examine the effects of a coexisting ventricular septal defect or short-term preparatory banding of the pulmonary artery before the arterial switch operation. Methods: Patients operated on from 1983 through 1991 were included. Echocardiographic and catheterization data were collected as part of a prospective evaluation of outcome in all patients who undergo the arterial switch operation at Boston Children's Hospital, with inclusion of data from the most recent catheterization only. Echocardiograms performed at least 6 months after the operation were included, with assessment of both the most recent status as well as serial trends. Whenever possible, echocardiographic evaluation included data necessary to perform analysis of ventricular mechanics including indices of afterload, preload, and contractility. Comparison was made to normal values and between subgroups defined on the basis of an arterial switch operation with or without ventricular septal defect and those who had a rapid two-stage arterial switch operation. Results: Invasive measures of left and right ventricular filling pressures, cardiac index, and pulmonary vascular resistance did not differ among the three groups. Overall, echocardiographic left ventricular end-diastolic dimension, wall thickness, mass, afterload (end-systolic wall stress), function (fractional shortening and rate-corrected velocity of fiber shortening), contractility (stressvelocity and stress-shortening relations), and preload were normal, and none of these variables was different between the groups with and without a ventricular septal defect. Serial evaluation indicated a slight but significant trend toward ventricular dilatation, perhaps related to a relatively high incidence of at least mild aortic regurgitation (30\%). In contrast, in the rapid two-stage group the echocardiographic indices of left ventricular function (fractional shortening and velocity of fiber shortening) and contractility (stress-velocity and stress-shortening relations) were found to be mildly but significantly reduced compared with normal subjects and with the other arterial switch operation groups. Over the duration of follow-up encompased by this study, no tendency toward progressive depression of function was seen. Conclusions: As the length of observation after the arterial switch operation continues to increase, left ventricular size, mass, functional status, and contractility continues to be normal, with no evidence of time-related deterioration of function. As previously reported, the rapid two-stage arterial switch operation does represent a higher risk for mild impairment of myocardial mechanics. (J THORAC CARDIOVASC SURG 1995;109:311-21)

Steven D. Colan, MD, Christine Boutin, MD,* Aldo R. Castañeda, MD, PhD, and Gil Wernovsky, MD, Boston, Mass.

From the Departments of Pediatrics and Surgery, Harvard Medical School, and the Departments of Cardiology and Cardiovascular Surgery, Children's Hospital, Boston, Mass.

Received for publication July 27, 1994.

Accepted for publication Nov. 7, 1994.

Copyright $(1) 1995$ by Mosby-Year Book, Inc.

$0022-5223 / 95 \$ 3.00+0 \quad \mathbf{1 2 / 1 / 6 2 0 4 5}$
Address for reprints: Steven D. Colan, MD, Department of Cardiology, Children's Hospital, 300 Longwood Ave., Boston, MA 02115.

*Current address: Christine Boutin, MD, Department of Cardiology, The Hospital for Sick Children, Toronto, Ontario, Canada. 
Numerous reports indicate that an arterial switch operation is preferable to intraatrial baffle repair for correction of transposition of the great arteries, in part because arrhythmias and ventricular dysfunction are less prevalent. ${ }^{1-5}$ Preservation of systemic ventricular function was a primary theoretical justification for consideration of the anatomic repair as potentially preferable to the repairs at the atrial level. It is therefore of considerable importance to critically examine the late status of the systemic ventricle in these patients, particularly since Graham and associates ${ }^{6}$ have observed a decreasing incidence of systemic right ventricular (RV) dysfunction in patients with a more recently performed atrial level repair of transposition of the great arteries. We have previously described our results in the initial cohort of patients with transposition of the great arteries and intact ventricular septum ${ }^{1}$ and transposition of the great arteries with ventricular septal defect ${ }^{5}$ at a mean follow-up of 1.5 years. We have also recently reported the results of analysis of myocardial mechanics in patients who have undergone preparatory pulmonary artery banding followed by arterial switch operation 1 to 2 weeks thereafter (rapid two-stage arterial switch operation). ${ }^{7,8}$ This report extends those observations to include a larger population of patients observed for up to 10 years and expands the observations to compare these groups with each other and with patients who had a rapid two-stage arterial switch operation. Throughout this manuscript we use the term rapid two-stage to refer to an arterial switch operation performed after a brief (1 to 2 week) period of preparatory pulmonary artery banding to distinguish this from the alternative approach of leaving the band in place for many months.

\section{Methods}

Patient selection. All patients who had undergone the arterial switch operation for transposition of the great arteries at Boston Children's Hospital from January 1, 1983, to December 31, 1991, were eligible for inclusion. These patients comprised three groups: (1) patients with transposition of the great arteries with intact ventricular septum or hemodynamically insignificant ventricular septal defect; (2) patients with transposition of the great arteries with ventricular septal defect sufficiently large to justify surgical closure, and (3) patients with transposition of the great arteries with low left ventricular (LV) pressure who had a rapid two-stage arterial switch operation consisting of banding of the pulmonary artery with an arterial switch operation 1 week to 2 months thereafter. ${ }^{7}$ Specifics of this patient population, including anatomic variations, age at repair, prior procedures, and other clinical data, have been reported in detail elsewhere. ${ }^{9}$ Case finding was performed by review of the computerized arterial switch operation database, which has been prospectively maintained since 1985 , with cross checks to the cardiology departmental clinical database at Children's Hospital. No patients were excluded from this review. Previous manuscripts have reported the results in the first 49 survivors of an arterial switch for transposition of the great arteries with intact ventricular septum ${ }^{1,2}$ and the first 62 patients undergoing an arterial switch operation with ventricular septal defect closure for transposition of the great arteries with ventricular septal defect. ${ }^{5}$ These patients are also included in this report. This study was approved by the Children's Hospital Human Investigation Committee in November 1992.

Follow-up protocol. Whenever geographically feasible, all patients after the arterial switch operation have been included in a prospective evaluation of outcome according to a protocol that we have previously reported. ${ }^{1,2,5}$ This protocol includes clinical evaluation, electrocardiography, use of a Holter monitor, echocardiography, and cardiac catheterization at about 1 year after the arterial switch operation and noninvasive evaluations annually thereafter. Because the majority of these patients are observed at other institutions, participation in the protocol at Children's Hospital in Boston is variable with a bias toward patients who live in the northeastern United States.

Review of clinical, catheterization, and echocardiographic data. Data collected in all eligible patients up to January 1, 1994, were reviewed, including all procedures and interventions and current clinical status. All catheterization data and angiograms were reviewed by one of us (G.W.) for pressure and saturation results, cardiac index, and any identified residua. Oximetry was used for detection of significant intracardiac shunting. $\mathrm{LV}$ and $\mathrm{RV}$ pressures and pressures above and below the arterial anastomoses were recorded and peak-to-peak gradients were calculated at each site. Hemodynamic measurements used in this analysis were taken before angiography or any interventional procedures. When there was significant respiratory variation in the ventricular end-diastolic pressure tracings, the mean right atrial and pulmonary capillary wedge pressures were substituted for RV and LV end-diastolic pressures, respectively. Values for cardiac index determined by the Fick method or by thermodilution were used to calculate pulmonary vascular resistance. We have previously described the immediate postoperative evolution of $\mathrm{LV}$ function after the arterial switch operation for transposition of the great arteries with intact ventricular septum ${ }^{1}$ and transposition of the great arteries with ventricular septal defect ${ }^{5}$ in detail. Therefore, only echocardiograms performed more than 6 months after arterial switch operation are included in this report. Only echocardiographic studies performed at our institution are included, to ensure standardization of methods used for assessment of ventricular mechanics. All available catheterization data were included whether obtained at Children's Hospital or at outside institutions.

Echocardiographic assessment. Patients were sedated with chloral hydrate, 50 to $100 \mathrm{mg} / \mathrm{kg}$, when judged necessary. The echocardiographic examination was performed with a Hewlett-Packard Sonos 500, 1000, or 1500 
(Hewlett-Packard Co., Palo Alto, Calif.) or an Acuson 128 echocardiographic machine (Acuson, Inc., Mountain View, Calif.). Transducers appropriate for body size were used. All examinations included two-dimensional echocardiographic imaging of the LV from subcostal, apical, and parasternal views. The presence and severity of aortic insufficiency was assessed by color Doppler echocardiography and graded on a four-point scale by measuring the size of the proximal regurgitant jet width on color Doppler echocardiography (absent; up to $4 \mathrm{~mm}$, mild; 4 to $6 \mathrm{~mm}$, moderate; $>6 \mathrm{~mm}$, severe). ${ }^{10}$ Patients with evidence of elevated RV systolic pressure by pulmonary or tricuspid regurgitation on Doppler echocardiography or RV volume overload owing to pulmonary or tricuspid regurgitation were excluded from quantitative analysis of cardiac mechanics. After a circular short-axis LV configuration throughout the cardiac cycle was confirmed by visual inspection, a high-speed $(100 \mathrm{~mm} / \mathrm{sec})$ hard-copy twodimensional echocardiogram-directed M-mode of the LV in the parasternal short axis was performed simultaneously with an electrocardiogram, a phonocardiogram, a carotid or axillary pulse tracing, and peripheral monitoring of the blood pressure. A Dinamap 845 vital signs monitor (Critikon, Inc., Tampa, Florida) was used to obtain brachial blood pressure.

Analysis of ventricular size, wall thickness, and mechanics. The indirect carotid or axillary pulse tracing in addition to the endocardial border of the ventricular septum and the endocardial and epicardial borders of the posterior wall of the $\mathrm{LV}$ on the M-mode recording were hand-digitized on a custom programmed microcomputerbased digitizing station by one of us. Measurements obtained by averaging data from three cardiac cycles were ventricular short-axis dimensions, LV posterior wall thickness, fractional shortening, mean velocity of circumferential fiber shortening corrected for heart rate (VCFc), LV mass calculated by the formula of Devereux and associates, ${ }^{11}$ and LV meridional wall stress calculated according to Grossman, Jones, and McLaurin ${ }^{12}$ :

$$
\mathrm{WS}=\frac{(\mathrm{P})(\mathrm{D}) 1.35}{(\mathrm{~h})(1-[\mathrm{h} / \mathrm{D}])(4)}
$$

where WS is the wall stress $\left(\mathrm{gm} / \mathrm{cm}^{2}\right), P$ is the pressure $(\mathrm{mm} \mathrm{Hg}), \mathrm{D}$ is the internal $\mathrm{LV}$ dimension $(\mathrm{cm}), \mathrm{h}$ is the $\mathrm{LV}$ posterior wall thickness $(\mathrm{cm})$, and 1.35 is the conversion factor from $\mathrm{mm} \mathrm{Hg}$ to $\mathrm{gm} / \mathrm{cm}^{2}$. End-diastolic dimension was taken as the maximum dimension. End-systolic measurements were determined at the first high-frequency component of the aortic valve closure sound recorded on the phonocardiogram. The end-systolic pressure was obtained by assigning the systolic pressure to the peak and the diastolic pressure to the nadir of the pulse tracing and calculation of intervening values by linear interpolation according to the method of Stefadouros, ${ }^{13}$ Marsh, ${ }^{14}$ and their coworkers.

The relation between VCFc and LV wall stress at end-systole has been previously shown to be a preloadindependent and afterload-adjusted index of contractility. ${ }^{15}$ In contrast, the relation between fractional shortening and end-systolic stress is a contractility index that is adjusted for afterload but sensitive to preload. These relationships were determined relative to a large population of normal controls and expressed as z-scores of the distribution in normal individuals, as follows. The relation of VCFc to end-systolic stress was calculated relative to the distribution of this relation in normal subjects as the stress-velocity index, defined as the number of standard deviations from the normal population mean VCFc for the given level of end-systolic stress. Thus a stress-velocity index of 0 is the normal mean value and the normal $95 \%$ confidence interval is -2 to 2 . The end-systolic stress/ fractional shortening relation was quantified as the stressshortening index, which is the number of standard deviations from the population mean fractional shortening for the given end-systolic stress. The effect of preload on LV performance is represented by the difference between these two indices and is quantified as the functional preload index, defined as stress-shortening index - stressvelocity index.

Statistical analysis. Values are reported as mean \pm 1 standard deviation unless otherwise indicated. To adjust for age and growth-related changes in ventricular mechanics, we expressed all echocardiographic variables as zscores relative to the normal distribution. Normal data for these parameters were determined in 180 normal children aged 1 week to 10 years studied in our echocardiographic laboratory by means of a similar protocol to the study population. This normal population has been described in detail previously. ${ }^{16}$ For fractional shortening, velocity of shortening, wall stress, and contractility, the $\mathrm{z}$-score relative to age was used; for LV dimension, wall thickness, and mass, the $z$-score relative to body surface area was used. Z-scores indicate the position of each measurement relative to the normal population expressed as standard deviations from the mean, where both the mean and standard deviations are specific for the age or body surface area (BSA). In addition, to facilitate comparison with data reported by others, we also report dimension, thickness, and mass appropriately adjusted for BSA. Linear measurements (dimension and wall thickness) were divided by $\mathrm{BSA}^{0.5}$ and mass by $\mathrm{BSA}^{1.5}$. Comparisons between groups were performed by analysis of variance. A Fisher exact test was used to compare groups regarding the prevalence of decreased contractility and aortic insufficiency. The relationship between time and the echocardiographic indices measured on the serial examinations was assessed by repeated-measures analysis of variance.

\section{Results}

Patients. A total of 470 patients have undergone the arterial switch operation for transposition of the great arteries at our institution during the 1983 through 1991 time interval. Of these, 254 had an arterial switch operation for transposition of the great arteries with intact ventricular septum, 190 had arterial switch operation for transposition of the great arteries with ventricular septal defect, and 26 had rapid two-stage arterial switch operation for transposition of the great arteries with low LV pressure. Prior surgical procedures had been per- 
formed in some patients. Among the patients with intact ventricular septum, two patients had coarctation repair and one had an atrial septectomy with Blalock-Taussig shunt. In the patients with ventricular septal defect, 49 had a prior operation (11 coarctation only, 14 pulmonary artery banding only, 15 coarctation with pulmonary artery band, 3 pulmonary artery band with repair of interrupted aortic arch, 3 pulmonary artery band and Blalock-Taussig shunt, 3 Blalock-Taussig shunt only). Over the entire study period there have been 40 deaths $(8.5 \%)$, with a mortality rate of $6.7 \%(17 / 254)$ in the intact ventricular septum group, $10.5 \%(20 / 190)$ in the ventricular septal defect group, and $11.5 \%(3 / 26)$ in the rapid two-stage group. Therefore, 430 patients were eligible for study inclusion.

Hemodynamic evaluation. Postoperative hemodynamic data were obtained at cardiac catheterization at a mean follow-up of 1.6 years after the operation (range 2 months to 10 years) in $330(76 \%)$ of the 430 hospital survivors, 184 of $237(78 \%)$ with intact ventricular septum, 127 of $170(74 \%)$ with ventricular septal defect, and 19 of $23(82 \%)$ with a rapid two-stage repair. For all patients, the mean cardiac index was $4.0 \pm 1.0 \mathrm{~L} / \mathrm{min}$ per square meter (range 2.0 to $8.0 \mathrm{~L} / \mathrm{min}$ per square meter). The end-diastolic pressure in the RV was $6 \pm 3 \mathrm{~mm} \mathrm{Hg}$ (range 1 to $15 \mathrm{~mm} \mathrm{Hg}$ ) and in the $\mathrm{LV}, 8 \pm 3 \mathrm{~mm} \mathrm{Hg}$ (range 3 to $18 \mathrm{~mm} \mathrm{Hg}$ ). The mean pulmonary artery pressure was $14 \pm 6 \mathrm{~mm} \mathrm{Hg}$ (range 7 to $73 \mathrm{~mm} \mathrm{Hg}$ ), with a mean pulmonary vascular resistance of $311 \pm$ 150 dynes $\cdot \mathrm{sec} \cdot \mathrm{cm}^{-5}$. (range 90 to 1770 dynes $\mathrm{sec} \cdot \mathrm{cm}^{-5}$ ). Comparison of the distribution of $\mathrm{LV}$ and RV end-diastolic pressures, cardiac index, and pulmonary vascular resistance among the three groups is shown in Fig. 1. For patients with hemodynamic data, two of the intact septum group and 33 of the ventricular septal defect group had surgical procedures before the arterial switch operation. As a group, the hemodynamic variables were not different in these patients compared with the group of patients who did not have a prior operation.

Echocardiographic evaluation. Of 430 late survivors, $364(84 \%)$ underwent echocardiographic evaluation 6 months or more after the operation (201/ $237=85 \%$ with intact ventricular septum, 142/170 $=83 \%$ with ventricular septal defect, and $21 / 23=$ $91 \%$ with rapid two-stage arterial switch operation). These examinations were performed $3.5 \pm 2.2$ years after the operation (range $=6$ months to 10.6 years). The mean duration of follow-up was not different among the three groups $(3.8 \pm 2.4$ years for intact ventricular septum, $3.2 \pm 2.0$ years for ventricular septal defect, and $3.2 \pm 1.4$ years for rapid two-stage group), although the maximum length of follow-up was shorter for the rapid two-stage group (5.3 years versus 10.6 years for intact ventricular septum group and 9.9 years for ventricular septal defect group). Of these, 160 of 364 (44\%) had quantitative analysis of ventricular mechanics at a latest median follow-up of $2.7 \pm 2.2$ years after the operation (96/184 [52\%] with intact ventricular septum, 45/142 [32\%] with ventricular septal defect, and 19/21 [90\%] with a rapid two-stage repair). Serial data consisting of two to four echocardiographic evaluations at more than 6 months after the operation were obtained in 58 patients. Seven of the ventricular septal defect group were among those patients who had surgical procedures before the arterial switch operation. Prior surgical procedure did not appear to affect any of the echocardiographic variables (by multivariate analysis of variance), and therefore results are not separately reported.

Aortic insufficiency. Because of the potential adverse effect of aortic regurgitation on myocardial mechanics, we report findings in this regard in detail. The number of patients in each group who also had echocardiographic evaluation of ventricular mechanics with no insufficiency, mild, moderate, or severe insufficiency of the neoaortic valve is shown in Table I. Data are shown for all patients who had late echocardiographic assessment. In addition, the data are shown for the subgroup of patients who had assessment of myocardial mechanics. Overall, $30 \%$ of patients had aortic regurgitation. The percent of patients with no regurgitation, mild, and moderate regurgitation was not different in the group of patients who had assessment of myocardial mechanics as in the group as a whole, implying that the effects of aortic regurgitation on myocardial mechanics should be adequately represented by the subgroup with available studies. The frequency of mild versus no regurgitation was significantly higher in the rapid two-stage arterial switch operation group than in the other groups.

LV mass, end-diastolic dimension, wall thickness, and end-systolic stress. The means for values indexed relative to BSA and for the BSA-relative z-scores of LV mass, end-diastolic dimension, and wall thickness for the transposition of the great arteries with intact ventricular septum, transposition of the great arteries with ventricular septal defect, and rapid two-stage arterial switch operation groups 

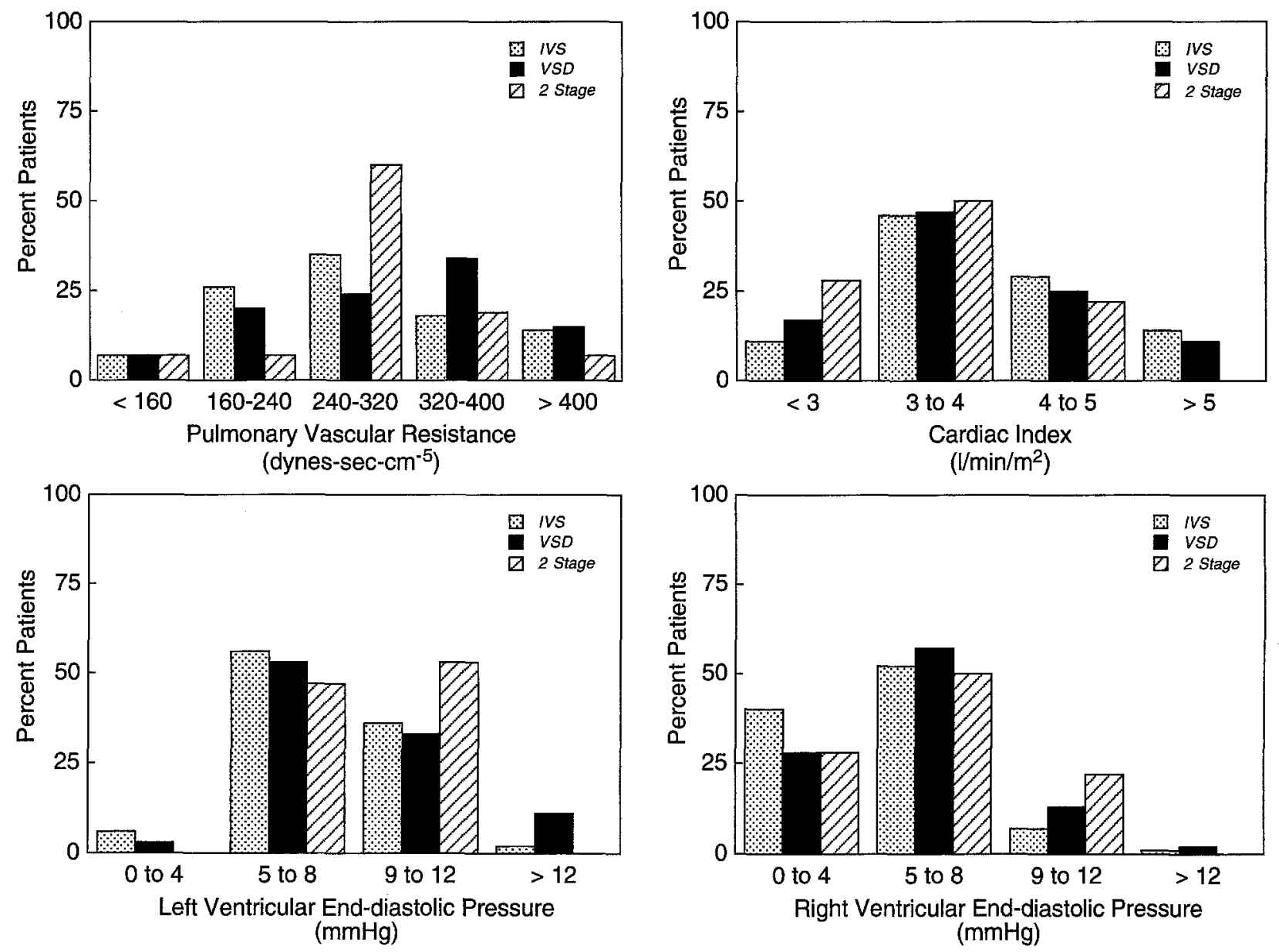

Fig. 1. Comparison of the distributions of RV end-diastolic pressure ( $\mathrm{mm} \mathrm{Hg}$ ), LV end-diastolic pressure ( $\mathrm{mm} \mathrm{Hg}$ ), cardiac index, and pulmonary vascular resistance (dynes $\cdot \mathrm{sec} \cdot \mathrm{cm}^{-5}$ ) in the three groups of patients (IVS, arterial switch operation in patients with transposition of the great arteries and intact ventricular septum; $V S D$, arterial switch operation in patients with transposition of the great arteries and ventricular septal defect; 2-Stage, rapid two-stage arterial switch operation). There were no significant differences among the three groups for the distribution of any of these variables.

are shown in Table II. The end-systolic wall stress and the age-relative end-systolic stress $z$-scores are also listed for each group. The data distributions for these variables are presented in Fig. 2.

LV systolic performance. For each of the three groups, the means for the echocardiographic function indices, as well as their age-relative z-scores, are indicated in Table II, and the data distribution is illustrated in Fig. 3. The mean value for each of these variables in the intact ventricular septum and ventricular septal defect groups was not significantly different from each other nor from the normal population mean value. However, for each of these four variables the rapid two-stage group had values that were significantly different from the other two groups and significantly below the normal range for age. LV function and contractility indices did not vary as a function of time since surgery in the group as a whole, or in any of the three subgroups. This issue was also separately addressed in the patients with serial examinations, as discussed later.

Serial evaluations and trends over time. Because of the absence of significant differences in outcome measures between the intact ventricular septum and ventricular septal defect groups identified at late evaluation and the limited number of serial evaluations of LV mechanics, we combined the available serial data in these two subgroups. We also exam- 
Table I. Incidence of aortic regurgitation classified according to severity in patients after arterial switch operation

\begin{tabular}{|c|c|c|c|c|c|c|c|c|c|c|c|c|}
\hline & \multicolumn{4}{|c|}{$I V S$} & \multicolumn{4}{|c|}{$V S D$} & \multicolumn{4}{|c|}{$2 S-A S O$} \\
\hline & \multicolumn{2}{|c|}{ All patients } & \multicolumn{2}{|c|}{$\begin{array}{l}\text { LV function } \\
\text { group }\end{array}$} & \multicolumn{2}{|c|}{ All patients } & \multicolumn{2}{|c|}{$\begin{array}{c}\text { LV function } \\
\text { group }\end{array}$} & \multicolumn{2}{|c|}{ All patients } & \multicolumn{2}{|c|}{$\begin{array}{l}\text { LV function } \\
\text { group }\end{array}$} \\
\hline & No. & $\%$ & No. & $\%$ & No. & $\%$ & No. & $\%$ & No. & $\%$ & No. & $\%$ \\
\hline None & 121 & 68 & 59 & 62 & 88 & 72 & 32 & 71 & 6 & 32 & 6 & 32 \\
\hline Mild & 53 & 30 & 35 & 37 & 30 & 25 & 12 & 27 & 13 & 69 & 13 & 69 \\
\hline Moderate & 4 & 2 & 2 & 2 & 4 & 3 & 1 & 2 & 0 & 0 & 0 & 0 \\
\hline Severe & 0 & 0 & 0 & 0 & 0 & 0 & 0 & 0 & 0 & 0 & 0 & 0 \\
\hline
\end{tabular}

$I V S$, Arterial switch operation in patients with transposition of the great arteries and intact ventricular septum; VSD, arterial switch operation in patients with transposition of the great arteries and ventricular septal defect; $2 S-A S O$, rapid two-stage arterial switch operation; All patients, results in all patients with late echocardiograms; LV function group, results in the subgroup of patients who had late assessment of myocardial mechanics.

Table II. LV echocardiographic parameters, presented as overall values and subdivided into groups

\begin{tabular}{lccc}
\hline & \multicolumn{1}{c}{ IVS } & \multicolumn{1}{c}{ VSD } & $2 S-A S O$ \\
\hline LVMi (gm/m ${ }^{3}$ ) & $94 \pm 28$ & $110 \pm 20$ & $109 \pm 40$ \\
LVMz (SD) & $-0.06 \pm 0.85$ & $1.01 \pm 1.98$ & $0.30 \pm 0.98$ \\
EDDi (cm/m) & $4.16 \pm 0.46$ & $4.17 \pm 0.47$ & $4.32 \pm 0.37$ \\
EDDz (SD) & $-0.15 \pm 2.87$ & $-0.17 \pm 2.16$ & $0.61 \pm 1.04$ \\
EDhi (cm/m) & $0.76 \pm 0.12$ & $0.84 \pm 0.24$ & $0.80 \pm 0.16$ \\
EDhz (SD) & $-0.04 \pm 1.06$ & $0.99 \pm 2.32$ & $0.26 \pm 1.36$ \\
ESS (gm/cm $\left.{ }^{2}\right)$ & $36.7 \pm 11.8$ & $34.2 \pm 14.2$ & $40.3 \pm 14.8$ \\
ESSz (SD) & $0.16 \pm 1.57$ & $-0.51 \pm 2.02$ & $0.73 \pm 1.94$ \\
VCFc (circ/sec) & $1.12 \pm 0.11$ & $1.12 \pm 0.12$ & $0.99 \pm 0.12^{*}$ \\
VCFcz (SD) & $-0.27 \pm 1.51$ & $0.12 \pm 1.61$ & $-2.02 \pm 1.59^{*} \dagger$ \\
FS (\%) & $36.9 \pm 3.5$ & $37.9 \pm 5.01$ & $33.6 \pm 3.9^{*}$ \\
FSz (SD) & $-0.23 \pm 1.44$ & $0.44 \pm 1.96$ & $-1.65 \pm 1.52^{* \dagger}$ \\
SVI (SD) & $0.08 \pm 1.35$ & $0.07 \pm 1.46$ & $-1.43 \pm 1.58^{* \dagger}$ \\
SSI (SD) & $0.12 \pm 1.58$ & $0.64 \pm 1.84$ & $-1.32 \pm 1.58^{* \dagger}$ \\
FPI (SD) & $0.04 \pm 0.96$ & $0.57 \pm 1.74$ & $0.11 \pm 0.97$
\end{tabular}

$\overline{I V S}$, Single-stage arterial switch operation in patients with transposition of the great arteries and intact ventricular septum; $V S D$, single-stage arterial switch operation in patients with transposition of the great arteries and ventricular septal defect; $2 S-A S O$, rapid two-stage arterial switch operation; $L V M i$ and $L V M Z$, LV mass, index to $\mathrm{BSA}^{1.5}$ and $\mathrm{z}$-score relative to BSA, respectively; $S D$, standard deviation; $E D D i$ and $E D D z$, LV end-diastolic dimension, indexed to BSA ${ }^{0.5}$, and z-score relative to BSA, respectively; $E D h i$ and $E D h z$, LV end-diastolic posterior wall thickness, indexed to BSA ${ }^{0.5}$, and z-score relative to BSA, respectively; $E S S$ and $E S S z$, end-systolic stress and z-score relative to age, respectively; $V C F C$ and $V C F C z$, rate-corrected velocity of fiber shortening and z-score relative to age, respectively; $F S$ and $F S z$, percent fractional shortening and z-score relative to age, respectively; SVI, stress-velocity index; SSI, stress-shortening index; $F P I$, functional preload index.

${ }^{*} p<0.05$ versus IVS and VSD groups.

$\dagger p<0.05$ versus normal range.

ined several variables (RV or LV outflow obstruction, severity of aortic regurgitation, and surgical procedures before arterial switch operation) to attempt to detect potential bias in the inclusion of patients in the subgroup who had serial assessment of $\mathrm{LV}$ function. The only factor that was different between those who did and did not have serial examinations available was severity of RV outflow obstruction (patients with significant RV outflow obstruction were excluded from assessment of myocardial mechanics). Ten of the 19 patients with rapid two-stage arterial switch operation had serial data and a total of 48 other patients had serial evaluation.
When serial trends were evaluated for each of the echocardiographic variables in each of the these two groups, several trends became apparent. In the patients after a one-stage procedure, LV mass and dimension z-score both demonstrated a significant direct relationship to length of follow-up, indicating an increase out of proportion to body growth. All other variables, including indices of function and contractility, showed no change with time. In the patients after a rapid two-stage arterial switch operation, there was a significant fall in wall thickness $z$-score and rise in dimension $z$-score with a consequent rise in end-systolic stress $z$-score over time. 

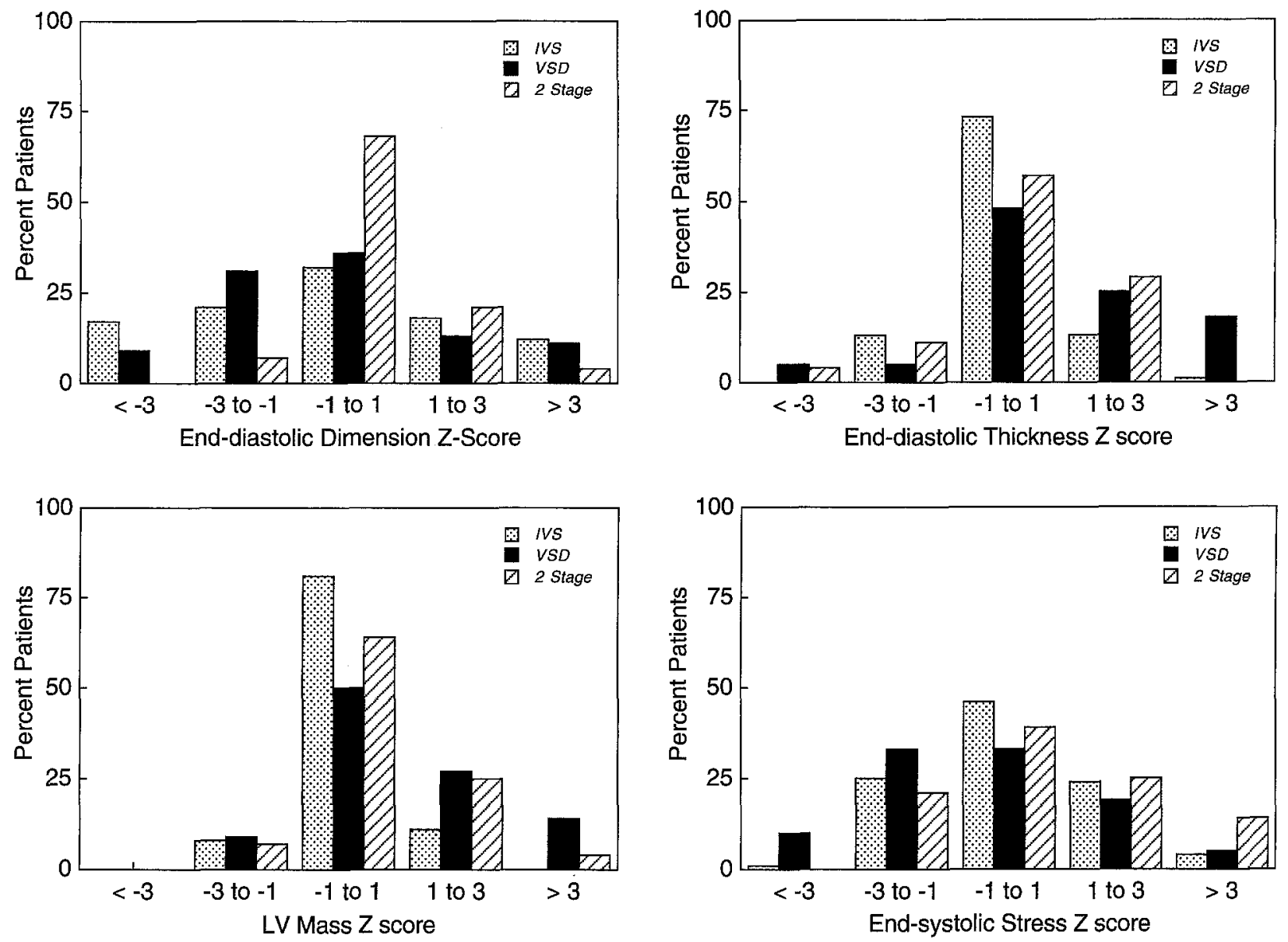

Fig. 2. Comparison of the distributions of LV end-diastolic dimension z-score (standard deviation), end-diastolic posterior LV wall thickness z-score (standard deviation), LV mass z-score (standard deviation), and end-systolic meridional wall stress $z$-score $\left(\mathrm{gm} / \mathrm{cm}^{2}\right)$ in the three groups of patients (abbreviations as in Fig. 1). There were no significant differences among the three groups for the distributions of any of these variables.

Similar to the one-stage group, indices of function and contractility showed no significant relationship to time since operation.

\section{Discussion}

In patients observed for up to 10 years after arterial switch operation in infancy for transposition of the great arteries with intact ventricular septum or with ventricular septal defect, we found cardiac index, LV filling pressures, dimension, wall thickness, and parameters of systolic function, loading conditions, and contractility to be normal. These findings confirm our previous observations reported earlier in the postoperative course of these patients. ${ }^{1,2,5}$ Also, as we have previously reported, ${ }^{8}$ patients who have undergone the rapid two-stage arterial switch operation contrast with these findings by manifesting mild depression of function and contractility. However, taken as a group, these findings support the hypothesis that improved preservation of systemic ventricular function can be achieved with the arterial switch operation compared with atrial level repair.

Previous reports. Other investigators have reported normal LV mass ${ }^{17}$ volume,${ }^{18}$ ejection fraction, ${ }^{17-21}$ dimension, ${ }^{22,23}$ shortening fraction, ${ }^{22-24}$ stress-velocity index, ${ }^{18,25}$ and stress-shortening in$\operatorname{dex}^{25}$ in patients who have previously undergone an arterial switch operation for transposition of the great arteries with either intact ventricular septum or ventricular septal defect. Although some investigators report depressed function after arterial 

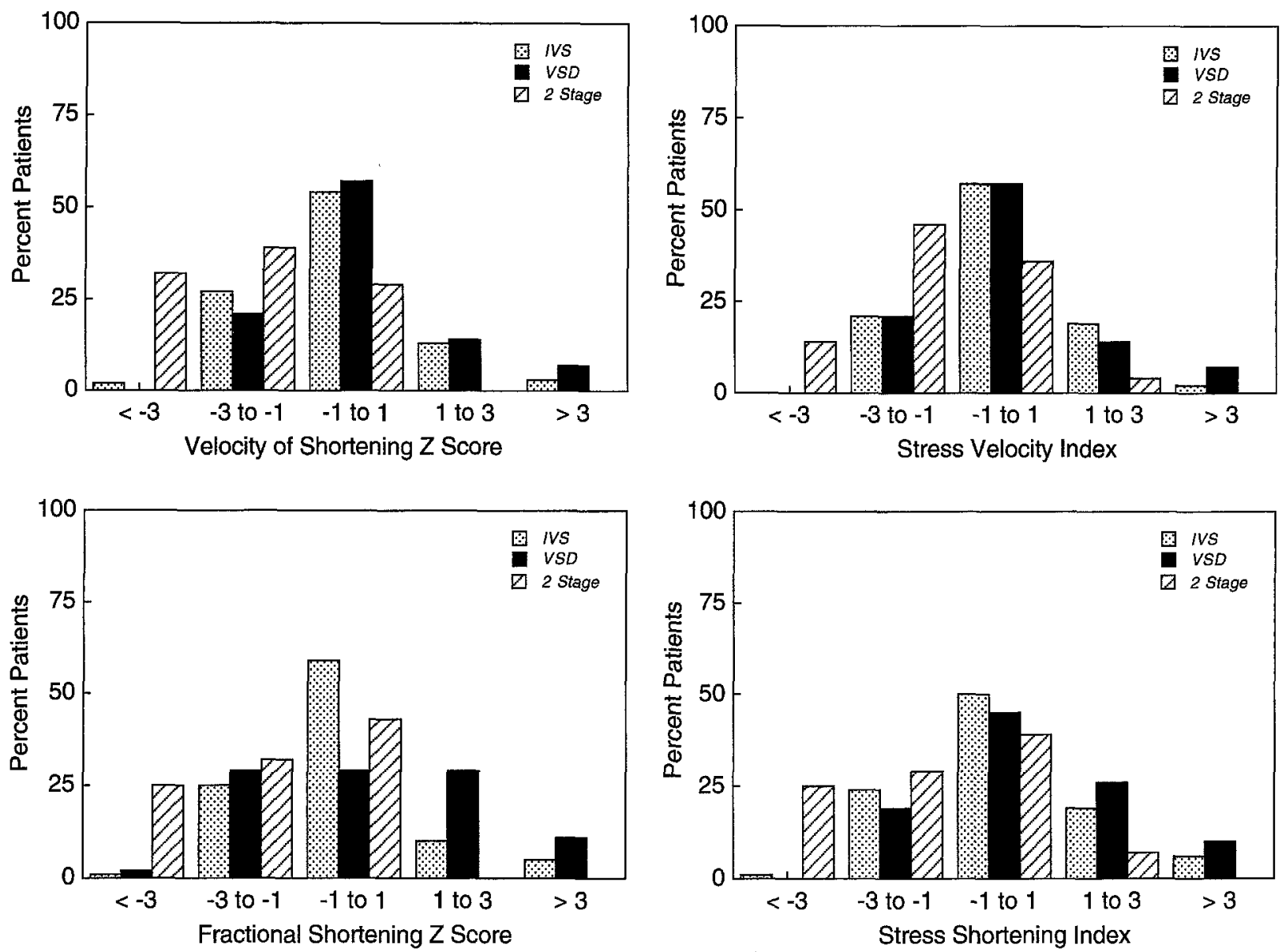

Fig. 3. Comparison of the distributions of LV rate-corrected velocity of fiber shortening z-score (standard deviation), fractional shortening z-score (standard deviation), stress-velocity index (standard deviation), and stress-shortening index (standard deviation), in the three groups of patients (abbreviations as in Fig. 1). For each of these variables the mean value in the rapid two-stage group was significantly lower than that for the other two groups and was also significantly different from that of the normal population mean.

switch operation, they have included patients who have undergone a prolonged period of preparatory pulmonary artery banding, ${ }^{26}$ making the data more difficult to interpret. Although elevated end-diastolic volume has been occasionally observed after arterial switch operation, ${ }^{20}$ a large percentage of these patients had residua (aortic regurgitation and residual ventricular septal defect) that appeared responsible. Because of the frequency of aortic regurgitation, ${ }^{10}$ enlarged bronchial collateral vessels, ${ }^{27}$ and occasional mild stenosis at the aortic anastomosis, mild elevation of $\mathrm{LV}$ mass and volume may be expected and does not imply abnormal myocardial function. In series that included patients who had undergone a two-stage arterial switch operation with a prolonged period of banding, a more globular then normal shape has been observed. ${ }^{28}$ However, we and others have found ventricular shape to be normal in groups that included only patients after primary repair or after rapid two-stage arterial switch operation, ${ }^{1,8,18}$

In addition to a more spherical LV shape, ${ }^{28}$ pulmonary artery banding of several months' duration followed by arterial switch operation has been reported to result in depressed contractility, $25,29,30$ abnormal regional wall motion, ${ }^{31}$ myocardial perfusion abnormalities, ${ }^{32}$ reduced ejection fraction, ${ }^{6,28}$ insufficiency of the neoaortic valve, ${ }^{23}$ and elevated LV volumes. ${ }^{33}$ These abnormalities do not appear to be progressive but have led to some concern about the ultimate outcome from this procedure. Our results show that the rapid two-stage arterial switch 
operation, in which the duration of preparatory banding is limited to 1 week, may not totally alleviate this concern. The degree of dysfunction we observed in these patients was mild, was not associated with symptoms, and did not progress on serial evaluation. Nevertheless, prolonged observation will be required to determine if this represents a significant long-term problem for this subgroup.

Review of serial data. Ventricular function and contractility were found to have no significant relationship to time since surgery for either the primary or rapid two-stage arterial switch operation groups. For the patients either with ventricular septal defect or with intact ventricular septum who underwent arterial switch operation without prior "preparatory" banding and had serial evaluation of ventricular mechanics, there was a small but significant trend toward increasing dimension and mass z-scores over time, implying that both increased at a rate greater than appropriate for the increase in body size. The hypertrophy was proportional to the rise in diameter, so that thickness/dimension and mass/volume ratio remained normal. The trend was similar in the rapid two-stage group although this did not achieve statistical significance over the shorter duration of follow-up in this patient group. The reason for this trend is not known, although the frequency of enlarged bronchial collaterals and relatively high incidence of aortic regurgitation, even if mild, may contribute.

Aortic regurgitation. Although, as observed in this study, insufficiency of the neoaortic valve has been observed frequently after the arterial switch operation, ${ }^{34}$ more than mild regurgitation has been unusual. The frequency of aortic regurgitation is greater in patients who have banding of the pulmonary artery before the arterial switch operation. The cause is uncertain. However, in addition to intrinsic differences between the aortic and pulmonary valves, which might lead to intolerance of the anatomic pulmonary valve to the force of the systemic circulation, and the fact that the surgical procedure itself could contribute because the neoaortic root is abnormal as a result of the coronary reimplantation sites and the aortic circumferential suture line, the pulmonary artery band may directly damage the valve mechanism. Should this damage prove to be progressive, the resulting LV volume load represents a potential risk for the myocardium.

Methodologic issues. The potential limitations of the echocardiographic method of analysis of ventricular mechanics used in this study have been previ- ously presented in detail. $15,16,35,36$ The analysis of ventricular mechanics based on M-mode measures of ventricular dimension and wall thickness is based on the assumptions that (1) ventricular configuration is normal, (2) the posterior wall thickness obtained on M-mode is representative of the circumferential average, and (3) regional wall motion is uniform. The first two of these issues must be addressed by two-dimensional imaging, which in our institution is done at the time of data collection. We have previously justified the third of these assumptions by confirming that ventricular shape and regional wall motion is normal in these patients as a group ${ }^{1}$ even in patients with a rapid two-stage arterial switch operation. ${ }^{8}$ Regional wall motion abnormalities have been reported in patients with the more prolonged banding preparatory peri$\operatorname{od}^{19,31}$ but were similarly noted to be absent after primary repair. ${ }^{31,37}$

A mild to moderate degree of $R V$ pressure and/or volume overload was prevalent in these patients because of insufficiency of the neopulmonary valve and stenosis at the pulmonary arterial anastomosis or branch pulmonary arteries. ${ }^{2,5}$ Because of interventricular interdependence ("crosstalk"), RV pressure and volume overload can affect both systolic and diastolic LV function. ${ }^{38-40}$ By necessity, patients in this category were excluded from analysis of ventricular mechanics. Consequently, we are unable to determine if patients after arterial switch operation with significant right-sided hemodynamic abnormalities have associated abnormalities of systemic ventricular function. In contrast, mild valvular and supravalvular aortic stenosis and aortic regurgitation, which are not uncommonly seen in these patients, ${ }^{10}$ do not interfere with the method of analysis used here. ${ }^{41}$

Limitations. Ideally, comprehensive serial evaluations of all patients should be performed. The limited number of patients from each group studied echocardiographically relates to the number of patients who are not followed up at our institution, as well as technical factors related to poor acoustic access or RV pressure or volume overload in some patients. Although the first two of these factors are unlikely to bias this analysis because they can be presumed to be random, abnormal right-sided hemodynamics are known to affect LV mechanics, and the results of this study may not be representative of the entire group. We previously found noninvasive parameters of diastolic function to be normal in these patients but did not address diastolic function 
in this study. This issue is likely to be of particular interest in the rapid two-stage group. Evaluation of the effect on diastolic function, as well as longer duration of follow-up, is needed before a more definitive conclusion can be reached as to outcome for this subgroup of patients. Although only $75 \%$ of patients have had postoperative catheterization, patients with no evidence of significant residual hemodynamic lesions were less likely to be referred for invasive evaluation, representing probable selection bias. Although the hemodynamic measurements in this report may thus not be representative of the entire arterial switch operation population, the results probably overestimate rather than underestimate the frequency of abnormal values.

Conclusions. The arterial switch operation results in excellent preservation of systemic ventricular function and myocardial contractility at up to 10 years of follow-up with no observed tendency toward deterioration. The rapid two-stage arterial switch operation is associated with a significant incidence of mild ventricular and myocardial dysfunction, and a longer period of observation is needed to determine the ultimate implications of this finding.

\section{REFERENCES}

1. Colan SD, Trowitzsch E, Wernovsky G, Sholler GF, Sanders SP, Castaneda AR. Myocardial performance after arterial switch operation for transposition of the great arteries with intact ventricular septum. Circulation 1988;78:132-41.

2. Wernovsky G, Hougen TJ, Walsh EP, et al. Midterm results after the arterial switch operation for transposition of the great arteries with intact ventricular septum: clinical, hemodynamic, echocardiographic, and electrophysiologic data. Circulation 1988;77:1333-44.

3. Bical O, Hazan E, Lecompte Y, et al. Anatomic correction of transposition of the great arteries associated with ventricular septal defect: midterm results in 50 patients. Circulation 1984;70:891-7.

4. Martin RP, Radley-Smith R, Yacoub MH. Arrhythmias before and after anatomic correction of transposition of the great arteries. J Am Coll Cardiol 1987; 10:200-4.

5. Di Donato RM, Wernovsky G, Walsh EP, et al. Results of the arterial switch operation for transposition of the great arteries with ventricular septal defect: surgical considerations and midterm follow-up data. Circulation 1989;80:1689-705.

6. Graham TP Jr, Burger J, Bender HW, Hammon JW, Boucek RJ, Appleton S. Improved right ventricular function after intra-atrial repair of transposition of the great arteries. Circulation 1985;72(Suppl):II45-51.
7. Jonas RA, Giglia TM, Sanders SP, et al. Rapid, two-stage arterial switch for transposition of the great arteries and intact ventricular septum beyond the neonatal period. Circulation 1989;80(Suppl):I203-8.

8. Boutin C, Wernovsky G, Sanders SP, Jonas RA, Castaneda AR, Colan SD. Rapid two-stage arterial switch operation: evaluation of left ventricular systolic mechanics after an acute pressure overload stimulus in infancy. Circulation 1994;90:1294-303.

9. Wernovsky G, Giglia TM, Jonas RA, Mone SM, Colan SD, Wessel DL. Course in the intensive care unit after "preparatory" pulmonary artery banding and aortopulmonary shunt placement for transposition of the great arteries with low left ventricular pressure. Circulation 1992;86(Suppl)II133-9.

10. Jenkins KJ, Hanley FL, Colan SD, Mayer JE Jr, Castaneda AR, Wernovsky G. Function of the anatomic pulmonary valve in the systemic circulation. Circulation 1991;84(Suppl):III173-9.

11. Devereux RB, Lutas EM, Casale PN, et al. Standardization of M-mode echocardiographic left ventricular anatomic measurements. J Am Coll Cardiol 1984;4: $1222-30$.

12. Grossman W, Jones D, McLaurin LP. Wall stress and patterns of hypertrophy in the human left ventricle. J Clin Invest 1975;56:56-64.

13. Stefadouros MA, Dougherty MS, Grossman W, Craige E. Determination of systemic vascular resistance by a noninvasive technique. Circulation 1973;47:101-7.

14. Marsh JD, Green LH, Wynne J, Cohn PF, Grossman W. Left ventricular end-systolic pressure-dimension and stress-length relations in normal human subjects. Am J Cardiol 1979;44:1311-7.

15. Colan SD, Borow KM, Neumann A. Left ventricular end-systolic wall stress-velocity of fiber shortening relation: a load-independent index of myocardial contractility. J Am Coll Cardiol 1984;4:715-24.

16. Colan SD, Parness IA, Spevak PJ, Sanders SP. Developmental modulation of myocardial mechanics: ageand growth-related alterations in afterload and contractility. J Am Coll Cardiol 1992;19:619-29.

17. Elkins RC, Knott-Craig CJ, Ahn JH, et al. Ventricular function after the arterial switch operation for transposition of the great arteries. Ann Thorac Surg 1994; 57:826-31.

18. Kramer HH, Rammos S, Krian A, et al. Intermediateterm clinical and hemodynamic results of the neonatal arterial switch operation for complete transposition of the great arteries. Int J Cardiol 1992;36:13-22.

19. Lincoln C, Redington AN, Li K, Mattos S, Shinebourne EA, Rigby ML. Anatomic correction for complete transposition and double outlet right ventricle: intermediate assessment of functional results. $\mathrm{Br}$ Heart J 1986;56:259-66.

20. Okuda H, Nakazawa M, Imai $Y$, et al. Comparison of ventricular function after Senning and Jatene proce- 
dures for complete transposition of the great arteries. Am J Cardiol 1985;55:530-4.

21. Yamaguchi M, Hosokawa $Y$, Imai $Y$, et al. Early and midterm results of the arterial switch operation for transposition of the great arteries in Japan. J THORAC CARDIOvasc Surg 1990;100:261-9.

22. Klautz RJ, Ottenkamp J, Quaegebeur JM, Buis Liem TN, Rohmer J. Anatomic correction for transposition of the great arteries: first follow-up (38 patients). Pediatr Cardiol 1989;10:1-9.

23. Martin MM, Snider AR, Bove EL, et al. Two-dimensional and Doppler echocardiographic evaluation after arterial switch repair in infancy for complete transposition of the great arteries. Am J Cardiol 1989;63:332-6.

24. Losay J, Planche C, Gerardin B, Lacour-Gayet F, Bruniaux J, Kachaner J. Midterm surgical results of arterial switch operation for transposition of the great arteries with intact septum. Circulation 1990;82(Suppl):IV14650.

25. Takahashi Y, Nakano S, Shimazaki Y, et al. Echocardiographic comparison of postoperative left ventricular contractile state between one- and two-stage arterial switch operation for simple transposition of the great arteries. Circulation 1991;84(Suppl):III180-6.

26. Martin RP, Qureshi SA, Ettedgui JA, et al. An evaluation of right and left ventricular function after anatomical correction and intra-atrial repair operations for complete transposition of the great arteries. Circulation 1990;82:808-16.

27. Wernovsky G, Bridges ND, Mandell VS, Castaneda AR, Perry SB. Enlarged bronchial arteries after early repair of transposition of the great arteries. J Am Coll Cardiol 1993;21:465-70.

28. Arensman FW, Radley-Smith R, Yacoub MH, et al. Catheter evaluation of left ventricular shape and function 1 or more years after anatomic correction of transposition of the great arteries. Am J Cardiol 1983;52:1079-83.

29. Borow KM, Arensman FW, Webb C, Radley-Smith $\mathrm{R}$, Yacoub MH. Assessment of left ventricular contractile state after anatomic correction of transposition of the great arteries. Circulation 1984;69:106-12.

30. Sievers HH, Lange PE, Onnasch DG, et al. Influence of the two-stage anatomic correction of simple transposition of the great arteries on left ventricular function. Am J Cardiol 1985;56:514-9.
31. Vogel M, Smalthorn JF, Trusler GA, Freedom RM. Echocardiographic analysis of regional left ventricular wall motion in children after the arterial switch operation for complete transposition of the great arteries. J Am Coll Cardiol 1990;15:1417-23.

32. Vogel M, Smallhorn JF, Benson LN, Gilday D, Freedom RM, Williams WG. Assessment of myocardial perfusion during stress and at rest in patients with transposition of the great arteries after arterial repair [Abstract]. Circulation 1987;76(Supp1):IV265.

33. Lange PE, Sievers HH, Onnasch DG, Yacoub MH, Bernhard A, Heintzen PH. Up to 7 years of follow-up after two-stage anatomic correction of simple transposition of the great arteries. Circulation 1986; 74(Suppl):I47-52.

34. Hourihan M, Colan SD, Wernovsky G, Maheswari U, Mayer JE Jr, Sanders SP. Growth of the aortic anastomosis, annulus, and root after the arterial switch procedure performed in infancy. Circulation 1993;88:615-20.

35. Colan SD, Sanders SP, Borow KM. Physiologic hypertrophy: effects on left ventricular systolic mechanics in athletes. J Am Coll Cardiol 1987;9:776-83.

36. Colan SD. Noninvasive assessment of myocardial mechanics - a review of analysis of stress-shortening and stress-velocity. Cardiol Young 1992;2:1-13.

37. Weindling SN, Wernovsky G, Colan SD, et al. Myocardial perfusion, function and exercise tolerance after the arterial switch operation. J Am Coll Cardiol 1994;23:424-33.

38. Slinker BK, Goto Y, LeWinter MM. Systolic direct ventricular interaction affects left ventricular contraction and relaxation in the intact dog circulation. Circ Res 1989;65:307-15.

39. Damiano RJ, La Follette P Jr, Cox JL, Lowe JE, Santamore WP. Significant left ventricular contribution to right ventricular systolic function. Am J Physiol Heart Circ Physiol 1991;261:H1514-24.

40. Milstein JM, Glantz SA. Mechanically increased right ventricular afterload alters left ventricular configuration, not contractility, in neonatal lambs. Pediatr Res 1993;33:359-64.

41. Borow KM, Colan SD, Neumann A. Altered left ventricular 'mechanics in patients with valvular aortic stenosis and coarctation of the aorta: effects on systolic performance and late outcome. Circulation 1985; $72: 515-22$. 